\title{
Response of Extreme Precipitation to Solar Activity and El Nino Events in Typical Regions of the Loess Plateau
}

\author{
H. J. Li, ${ }^{1,2,3}$ J. E. Gao, ${ }^{1,2,3}$ H. C. Zhang, ${ }^{2}$ Y. X. Zhang, ${ }^{2,4}$ and Y. Y. Zhang ${ }^{5}$ \\ ${ }^{1}$ Institute of Soil and Water Conservation, Chinese Academy of Sciences and Ministry of Water Resources, Yangling, \\ Shaanxi Province 712100, China \\ ${ }^{2}$ Northwest A\&F University, Yangling, Shaanxi Province 712100, China \\ ${ }^{3}$ University of Chinese Academy of Sciences, Beijing 100049, China \\ ${ }^{4}$ Hunan Provincial Water Resources Department, Changsha, Hunan Province 410007, China \\ ${ }^{5}$ Ansai County Meteorological Bureau, Ansai, Shaanxi Province 717400, China \\ Correspondence should be addressed to J. E. Gao; gaojianen@126.com
}

Received 6 November 2016; Revised 26 February 2017; Accepted 2 March 2017; Published 10 April 2017

Academic Editor: Harry D. Kambezidis

Copyright @ 2017 H. J. Li et al. This is an open access article distributed under the Creative Commons Attribution License, which permits unrestricted use, distribution, and reproduction in any medium, provided the original work is properly cited.

\begin{abstract}
Extreme climatic oscillation has been the subject of global attention. The purpose of this study is to explore the response of extreme precipitation to solar activity and El Nino events in typical regions of the Loess Plateau-a case study in the Yan'an area. The precipitation data was from nine weather stations in Yan'an and the sunspot number and the Southern Oscillation Index (SOI) were from 1951 to 2015. The results show that maximum precipitation occurred mainly at the peak sunspot number or $2 \mathrm{a}$ near it and the sunspot number minimum and valley values were not significantly correlated. The results of Morlet wavelet showed that a 41-year period of precipitation was the most obvious within the 64-year scale. Similarly, sunspot number showed a 16-year periodic variability. Correlation analyses of the 16-year and 41-year scales demonstrated that the relationships between precipitation and sunspot number were close. In addition, extreme precipitation often occurred in the year following El Nino events. According to 10 -year moving average curves, precipitation generally showed a downward trend when SOI was negative. The results indicate that solar activity and El Nino events had significant impacts on precipitation in typical regions of the Loess Plateau.
\end{abstract}

\section{Introduction}

According to the IPCC AR4, atmospheric temperature has increased globally, a trend that is closely related to greenhouse gas emissions and land-cover and land-use changes. Global climate change is characterized by climate warming, and concomitant changes in extreme climates have seriously affected many aspects of the environment and economic development, as well as social stability, at global and regional scales. A warmer climate may also lead to increases in extreme precipitation in many world regions.

The Loess Plateau of China has historically suffered from considerable soil erosion, resulting in severe environmental and economic problems, such as desertification, rangeland degradation, and channel deposition [1]. In the Loess Plateau, severe soil erosion is often caused by infrequent heavy rain and storms and extreme precipitation [2]. Exploring the variation and occurrence of regional extreme precipitation under climate change is crucial to help evaluate potential risks to soil erosion and to take adaptive measures in advance.

Many studies have been undertaken to access the changing trends of extreme precipitation in different world regions, such as Europe, North America, Africa, India, and China. The occurrence of most extreme precipitation is influenced by many factors, such as solar activity, El Nino South Oscillation, global warming, or human activities.

Solar activity, such as solar winds, flares, and solar radiation bursts, can lead to plasma movement and radiation enhancement [3, 4]. Many scholars have researched the periodic variation of solar activity $[5,6]$ and shown that the solar cycle has important impacts on climate change in a wide variety of ways. In addition, the solar cycle significantly 


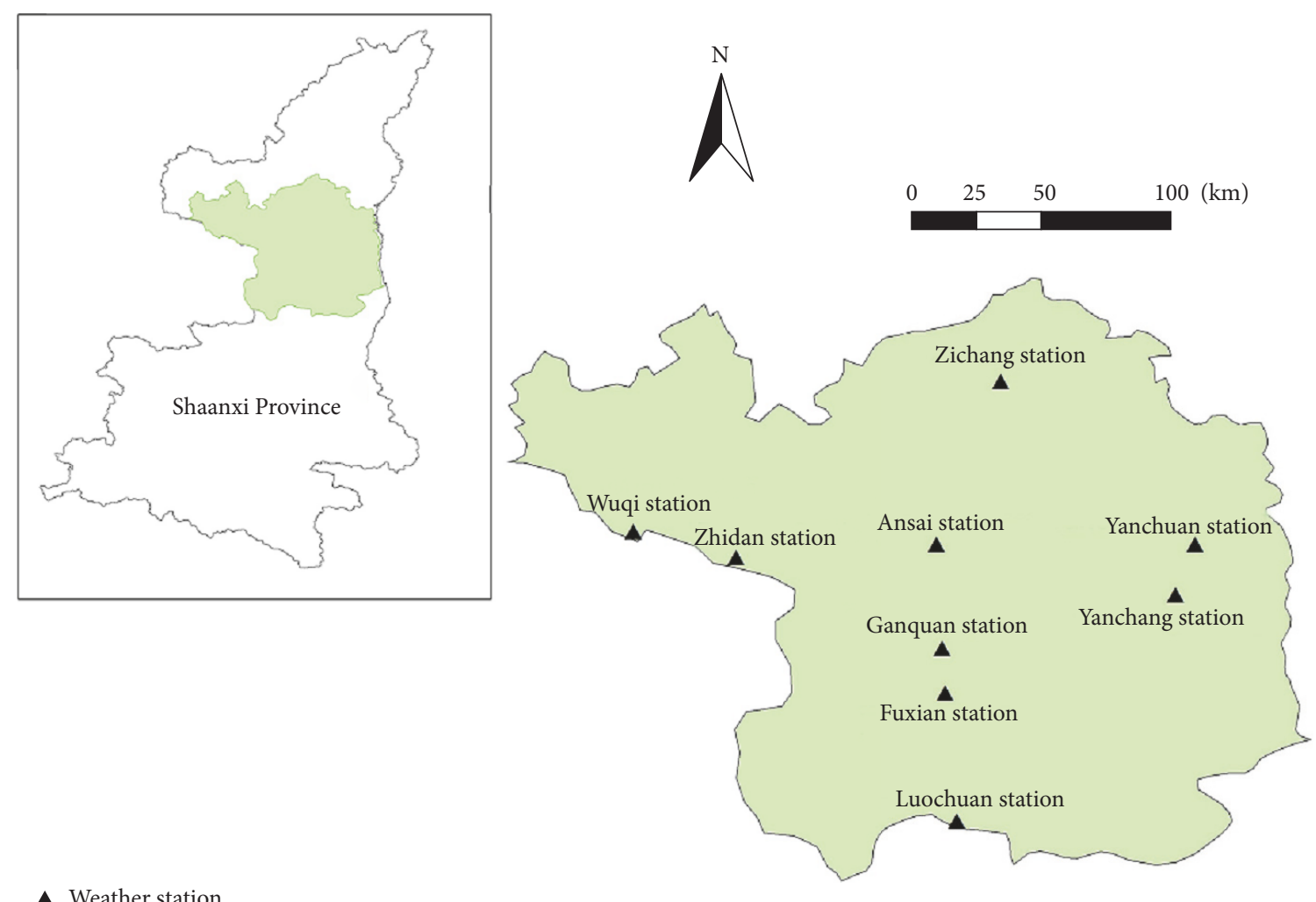

FIgURE 1: Spatial distribution of the nine weather stations in the Yan'an area.

influences regional hydrometeorological phenomenon [7]. Previously, a number of studies have investigated the relationships between solar activity and runoff, precipitation, and intense loess erosion using statistical methods [3]. These studies revealed close relationships between solar activity and hydrometeorological processes. El Nino is a well-known global scale ocean-atmospheric coupled phenomenon over the tropical Pacific. The El Nino Southern Oscillation (ENSO) has a strong influence on interannual precipitation variability in many parts of the world [8]. The same ENSO events may be linked with droughts or floods in different regions.

There have been many studies on the relationships between extreme precipitation and solar activity and El Nino worldwide. However, adequate study of the Loess Plateau is still required. Under the background of global climate change, extreme precipitation occurs frequently. Analyzing the variation and mechanism of extreme precipitation in the Loess Plateau and predicting the future trends are urgently needed. In this paper, we take Yan'an as a case study to analyze the long-term precipitation series in Yan'an from 1951 to 2015 based on the Morlet wavelet method and then evaluate the relationship between extreme precipitation, sunspots, and El Nino events. First, a Morlet wavelet method was introduced to analyze the correlation between extreme precipitation and sunspots. Then, a statistical method was used to analyze the connection between extreme precipitation and El Nino events. Finally, the relationship among extreme precipitation, sunspots, and El Nino events was explored based on wavelet coefficients and statistical results, and the possible effects of the sunspots and El Nino events on extreme precipitation of the Loess Plateau are discussed.

\section{Study Area, Data, and Methods}

2.1. Study Area. The Yan'an area is an area of serious soil erosion in the loess hilly gully region, covering approximately $37,000 \mathrm{~km}^{2}$ within Shaanxi Province. Its geographical position $\left(35^{\circ} 21^{\prime} \sim 37^{\circ} 31^{\prime} \mathrm{N}, 107^{\circ} 41^{\prime} \sim 110^{\circ} 31^{\prime} \mathrm{E}\right)$ is in the middle of the Loess Plateau (Figure 1). The area is located in a typical warm temperate continental monsoonal climatic region with a mean annual precipitation of approximately $500 \mathrm{~mm}$, and more than $70 \%$ of the precipitation is distributed from June to September. The mean temperature varies from 7.7 to $10.6^{\circ} \mathrm{C}$. The Yan River is the primary river in the study area and is a first-order branch of the Yellow River. Due to poor corrosion resistance and loose soil particles, soil is prone to erosion. In 2013, the annual Yan'an precipitation was the highest in 100 years and caused serious soil erosion.

2.2. Data. The long-term daily precipitation series at nine meteorological stations (Wuqi, Zichang, Zhidan, Ansai, Ganquan, Yanchuan, Yanchang, Fuxian, and Luochuan stations) in the Yan'an areas from 1951 to 2015 were obtained from the China Meteorological Science Data Sharing Service Network (http://www.escience.gov.cn/metdata/page/index.html). The annual sunspot numbers during the period of 1951-2015, 
which were obtained from the National Aeronautics and Space Administration (http://solarscience.msfc.nasa.gov/SunspotCycle.shtml), were used for solar activity analyses.

Large-scale climatic conditions have been successfully evaluated using the Southern Oscillation Index (SOI) [9]. The SOI is an inverse correlation of the atmospheric pressure between the tropical Pacific and the tropical Indian Ocean and is computed using the standardized anomaly of the mean sea level pressure (MLSP) difference between Tahiti and Darwin. When the SOI is negative, there is an El Nino phenomenon. The Sea Level Press standardized data from 1951 to 2015 were obtained from the National Oceanic and Atmospheric Administration (NOAA) (http://www.cpc.ncep.noaa .gov/data/indices/). The formula used is as follows:

$$
\mathrm{SOI}=10 \frac{P_{\text {diff }}-P_{\text {diffav }}}{\mathrm{SD}\left(P_{\text {diff }}\right)}
$$

where $P_{\text {diff }}$ is (average Tahiti MSLP for the month) - (average Darwin MSLP for the month), $P_{\text {diffav }}$ is long-term average of $P_{\text {diff }}$ for the month of study, and $\operatorname{SD}\left(P_{\text {diff }}\right)$ is long-term standard deviation of $P_{\text {diff }}$ for the month of study. The multiplication by 10 is a convention that results in whole number SOI ranges from about -35 to +35 .

All data used in this study have been checked for quality control by corresponding agencies and are of good quality.

\subsection{Method}

2.3.1. Wavelet Analysis. The wavelet transform (WT) has been a major development in the field of data analysis since the 1980s. WT is an effective means to process time series data, especially those with nonstationary characteristics [10]. It is frequently applied in hydroclimatic time series [11, 12]. In this paper, the complex Morlet wavelet is mainly used to analyze the variation tendency and periodicity in precipitation and sunspot numbers, their interrelationships, and interannual variability.

The wavelet function in this paper is the complex Morlet wavelet, which was defined as

$$
\psi(t)=\frac{1}{\sqrt{\pi f_{b}}} e^{2 i \pi f_{c} t} e^{-t^{2} / f_{b}},
$$

where $\psi(t)$ is the complex conjugate of the wavelet function $\psi(t)$ (the mother wavelet), $f_{b}$ is a bandwidth parameter, and $f_{c}$ is a wavelet center frequency. In this study, $f_{b}: f_{c}=1.5: 1$, and $i$ denotes the imaginary part. The real-value Morlet is the real part of the complex version of the Morlet wavelet. The real part and imaginary part exist with a phase difference of $\pi / 2$ to eliminate oscillations so that the results are more accurate.

A complex Morlet wavelet provides important pieces of information including (a) the modulus for energy density; (b) the phase that detects singularities and measures instantaneous frequencies; (c) the real part of the wavelet coefficient that depicts both the intensity and phase of the signal variation, at particular, scales and locations in wave domain (the time-frequency domain); and (d) the second power of modulus that represents the energy spectrum and

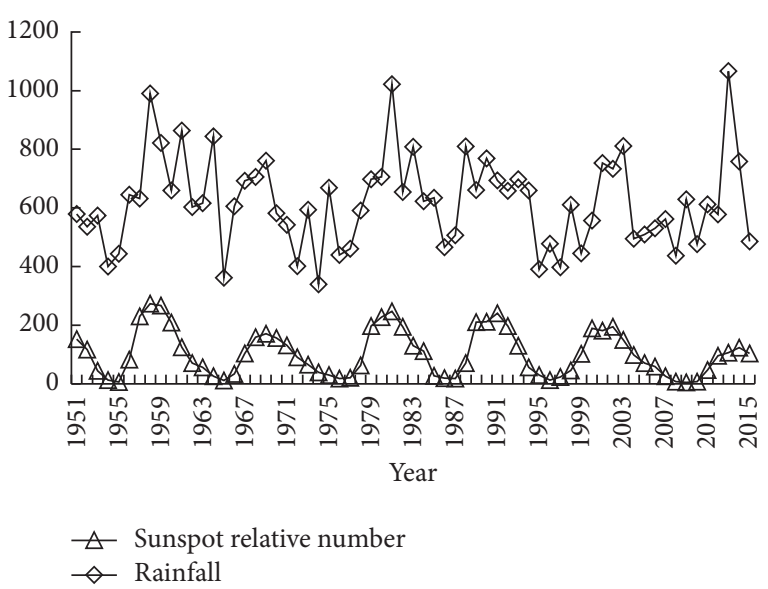

FIGURE 2: Variation in precipitation in the Yan'an area and sunspot number.

shows the energy variability at particular scales. In general, a greater modulus results in a clearer periodic change at a corresponding scale and time. The real part of the wavelet coefficients has a similar ability, which is applied to the structures of one time series on different scales. The main period of the time series is obtained by wavelet variance, which can be expressed as

$$
\operatorname{Var}(a)=\sum\left(W_{f}\right)^{2}(a, b),
$$

where $\operatorname{Var}(a)$ is the wavelet variance, $\left(W_{f}\right)(a, b)$ is the wavelet coefficient, $a$ is the frequency/scale variable, and $b$ is the time variable. The largest peak value has the strongest oscillation, which is used to analyze the oscillation variation and average period for precipitation and sunspot numbers. The second and third largest peak values correspond to the second and third main periods.

2.3.2. Statistical Analysis and Trend Detection. The mean, the maximum, and the minimum were used to calculate precipitation. The mean and the standard deviation were used for SOI. The correlation between sunspot and precipitation was analyzed by regression analysis.

When the difference between the annual precipitation and its annual mean value is more than the double meansquare deviation, it is defined as extreme precipitation (definition from the World Meteorological Organization).

\section{Results and Discussion}

3.1. Wavelet Analyses of Precipitation and Sunspot Number. The annual precipitation at Yan'an station from 1951 to 2015 was highly nonstationary and nonlinear, which had no clear periodic fluctuation (Figure 2). In the research, the sunspot number was used for solar activity analyses. Unlike precipitation, the sunspot number showed a clear period (Figure 2). Compared with the statistics of precipitation and sunspot number, the precipitation trend in the Yan'an area and sunspot number were consistent (Figure 2). With an increase in sunspot number, the precipitation in the 
Yan'an area increased. The maximum precipitation occurred mainly at the peak of sunspot number or 2 a near it. From Figure 2, there were five peak values for sunspot number from 1951 to 2015 . They were 1958, 1969, 1980, 1990, and 2002; in comparison, the maximum precipitation occurred in 1958 (716.53 mm), 1969 (589.29 mm), 1981 (775 mm), 1988 $(739.29 \mathrm{~mm})$, and $2003(660.7 \mathrm{~mm})$. The results were similar to those of $\mathrm{Li}$ and Yang [13], who also reported that the annual precipitation at the Yellow River showed hysteresis for sunspot number. Zhang et al. [14] reported that, at the peak of sunspot activity or $2 \mathrm{a}$ near it, the summer precipitation in Xi'an increased sharply. When the sunspot number was in decline, the precipitation showed a downward trend. However, the minimum precipitation and valley value for sunspot number were not significantly correlated relationships. There were six valley values for sunspot numbers from 1951 to 2015, which were 1955, 1964, 1975, 1987, 1998, and 2009, and the corresponding precipitation was in 1955 (434.1 $\mathrm{mm})$, 1964 (817.8 mm), 1975 (639.3 mm), 1987 (489.3 mm), 1998 (564.3 mm), and 2009 (625 mm), respectively.

To decompose the original data and analyze the period of sunspot number and precipitation, the wavelet analyses method was introduced in this research. The 64-year scale was chosen, and the wavelet coefficient contour map of the precipitation time series was plotted based on the Morlet wavelet method. The wavelet map represents the correlation of the wavelet with the signal. The wavelet transform can be analyzed through the real part, the modulus, and the second power of modulus of the wavelet. The intensity at each $x-y$ point represents the magnitude of the wavelet coefficients. The real part of the complex Morlet wavelet coefficient includes both the phase and intensity of the signal transformation, at particular locations and scales in the timefrequency domain. In the precipitation wavelet coefficient, a positive real part coefficient denotes that the precipitation was higher and vice versa. From the real part periodic variability, the precipitation structures with higher flow and lower flow phases were clearly shown on different scales. The lower scales were more complex and nested into higher scales.

The real part of the precipitation at Yan'an station in the Loess Plateau during 1951-2015 is plotted in Figure 3(a). In the figure, the red zone represents higher precipitation, the blue zone indicates lower precipitation, and other colors show middle precipitation. As shown in Figure 3(a), the precipitation varied from scales of 28-48 years, with 10-year periodical characteristics within a 64-year scale. On a $28-48-$ year scale, there were more than two-cycle oscillations. The periods of 1956-1967, 1979-1994, and 2008-2015 were the high-precipitation periods, while 1951-1955, 1967-1979, and 1994-2008 were the low-precipitation periods. The precipitation remained a high-precipitation period after 2015. From the wavelet variance (Figure 4(a)), the 41-year period was the most significant on a 64-year scale. Its real part wave coefficients changes on a 41-year scale are shown in Figure 4(b). On a 10-year scale, there were more cycle oscillations. The oscillation frequency was complicated and high.

The modulus of the wavelet coefficient represents the power density, which showed the periodic variability over different time scales (Figure 3(b)). For the modulus and
TABLE 1: Correlation coefficients of the WT real part coefficient series of 16- and 41-year scales between sunspot number and precipitation at Yan'an station from 1951 to 2015.

\begin{tabular}{lcc}
\hline Time scale & Pearson correlation coefficients & Sig. level \\
\hline 16 & 0.784 & 0.000 \\
41 & 0.893 & 0.000 \\
\hline
\end{tabular}

second power, higher values indicated a more obvious periodic variability in scale and time. In Figure 3(a), there was obvious periodic variability with $28-45$ years, 51-64 years, and less than 10 years. The second modulus power represents the energy spectrum, which shows energy variability over different time scales. From Figure 3(c), there was one center of energy.

As with the wavelet analyses of precipitation, the sunspot number from 1951 to 2015 was also decomposed on a 64year scale using the Morlet wavelet. The real part, modulus, and second modulus power of the wavelet coefficient of the sunspot number are shown in Figures 5(a)-5(c). The sunspot number showed dramatic periodic variability, especially on a 16-year scale, and there were two energy centers on about the 16-year scale in the modulus and the second power of the wave coefficient. From the wavelet variance (Figure 6(a)), the 16-year period was the most significant on a 64-year scale. Its real part wave coefficients changed on a 41-year scale, as shown in Figure 6(b).

As shown in Figures 4(a) and 6(a), the precipitation and sunspot numbers had 41- and 16-year periods, respectively. Therefore, the possible impacts of solar activity on precipitation at Yan'an station showed 16- and 41-year features. In the study, their real part wavelet coefficient series for 16-year and 41-year scales were applied to analyze their correlations. The correlation coefficients were 0.784 and 0.893 , respectively (Table 1), showing high correlations from 1951 to 2015. These results showed that the relationships between sunspot number and precipitation were close and that solar activity had significant impacts on precipitation at Yan'an station.

From Figure 5(a), the new solar activity week (the twentyfourth) began since 2009 and reached a maximum value in 2013-2014. Based on Figure 2, the annual Yan'an precipitation in 2013 was $959.1 \mathrm{~mm}$, the highest in 100 years. In addition to the maximum month, the maximum and the annual precipitation all reached historic, extreme values. This phenomenon again verified the results above.

3.2. Correlations between Precipitation and El Nino. Prestes et al. [15] showed that regional precipitation anomalies, floods, and other disasters all have good response relationships to solar activity, global climate anomalies, atmospheric circulation, and El Nino events. Figure 7 shows that precipitation in the Yan'an area continuously fluctuates. The maximum and minimum precipitation differed greatly, and precipitation anomalies exist. For years with anomalies, the precipitation time series data were examined to identify changes associated with the large-scale circulation modes of the Southern Oscillation Index (SOI). El Nino referred to positive anomalies in sea surface temperature (SST) for eastern and 


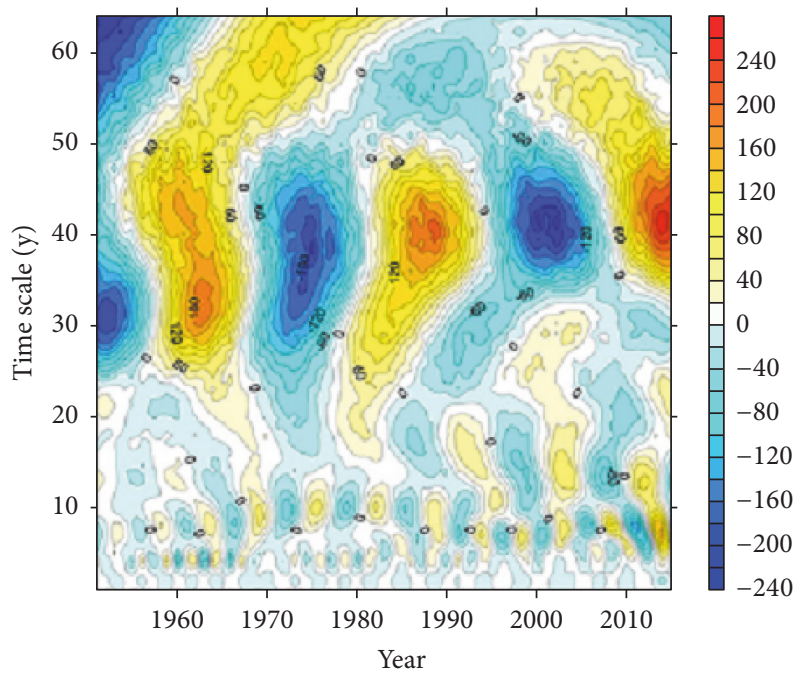

(a)

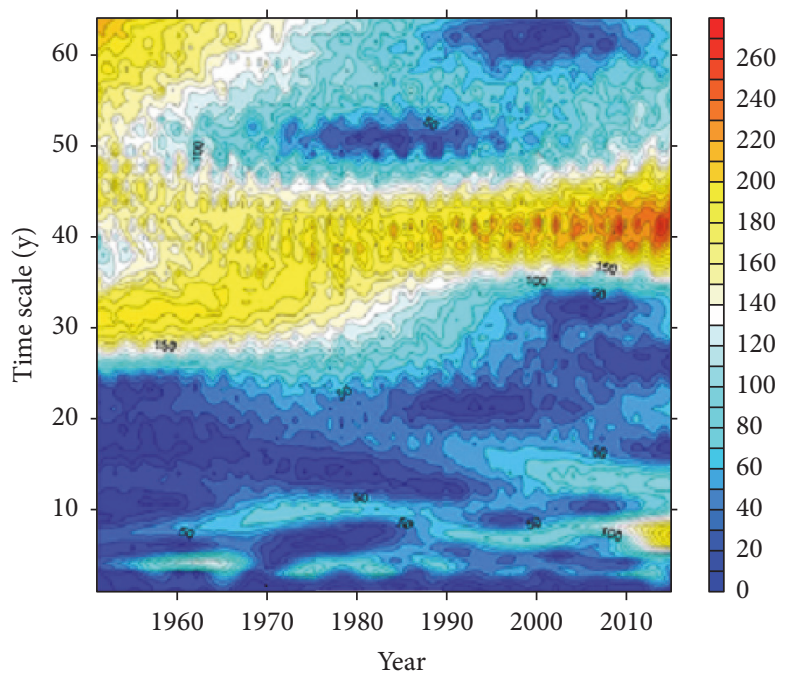

(b)

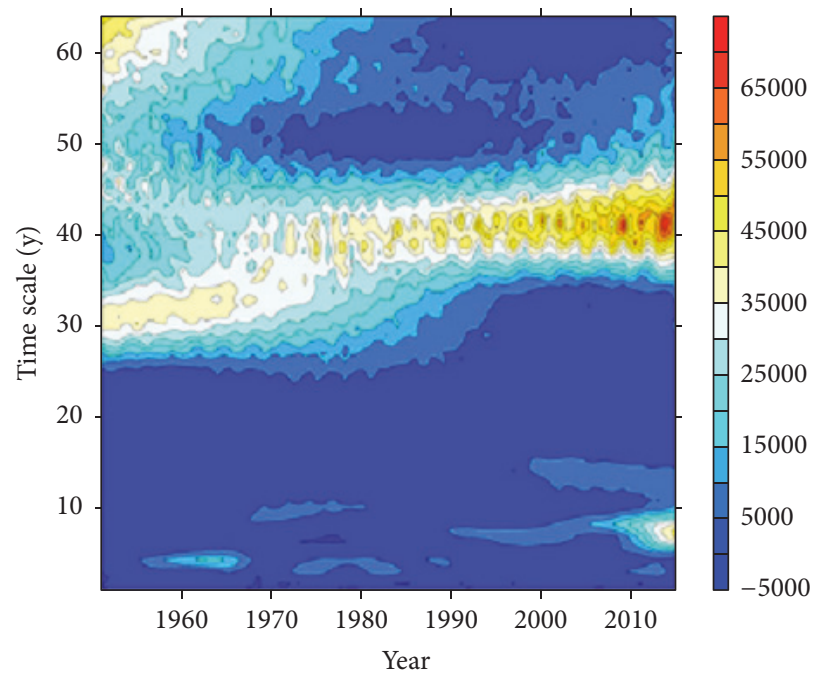

(c)

FIGURE 3: The real part, modulus, and the second power of the modulus of the wavelet coefficient contour of precipitation: (a) real part wavelet coefficient contour map of precipitation; (b) modulus of wavelet coefficient contour map of precipitation; (c) the second power of the modulus of the wavelet coefficient contour map of precipitation.

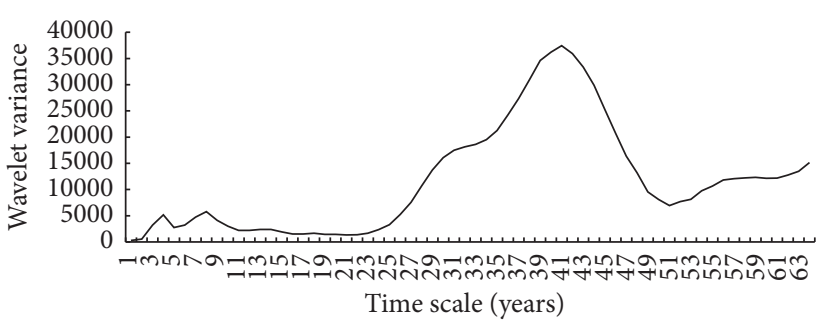

(a)

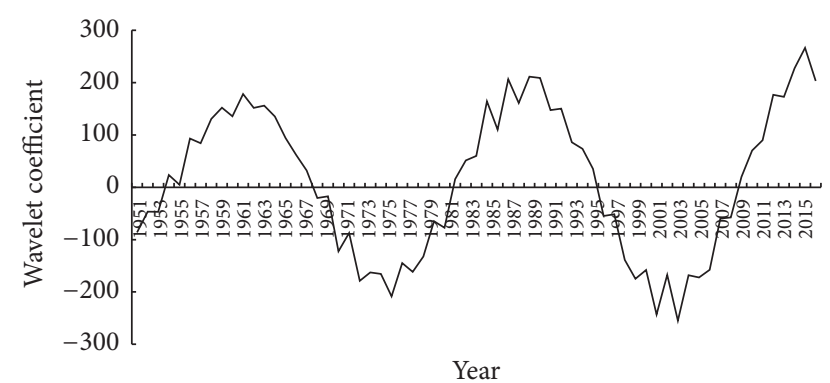

(b)

FIGURE 4: Wavelet variance and real part coefficient change in precipitation: (a) wavelet variance of precipitation; (b) real part coefficients change in precipitation on a 41-year scale. 


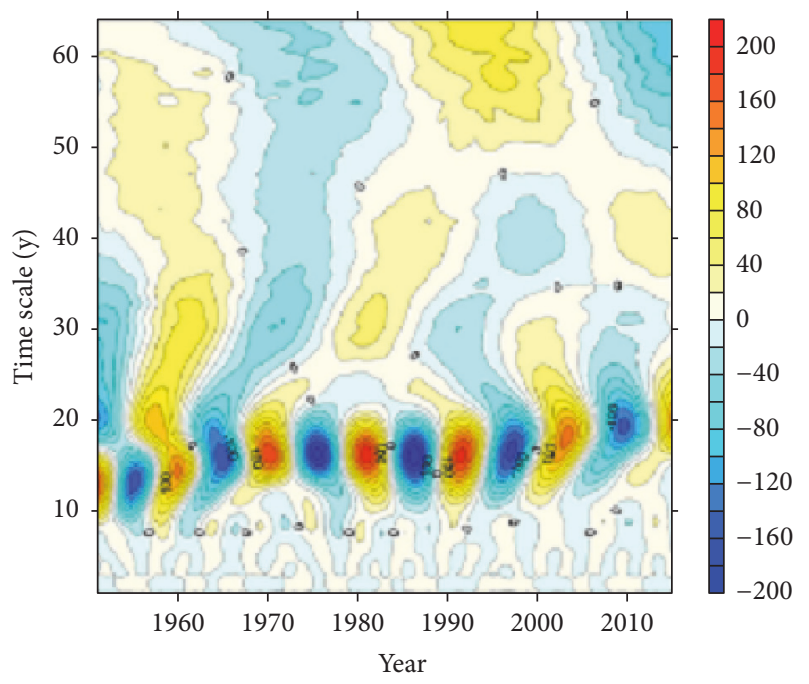

(a)

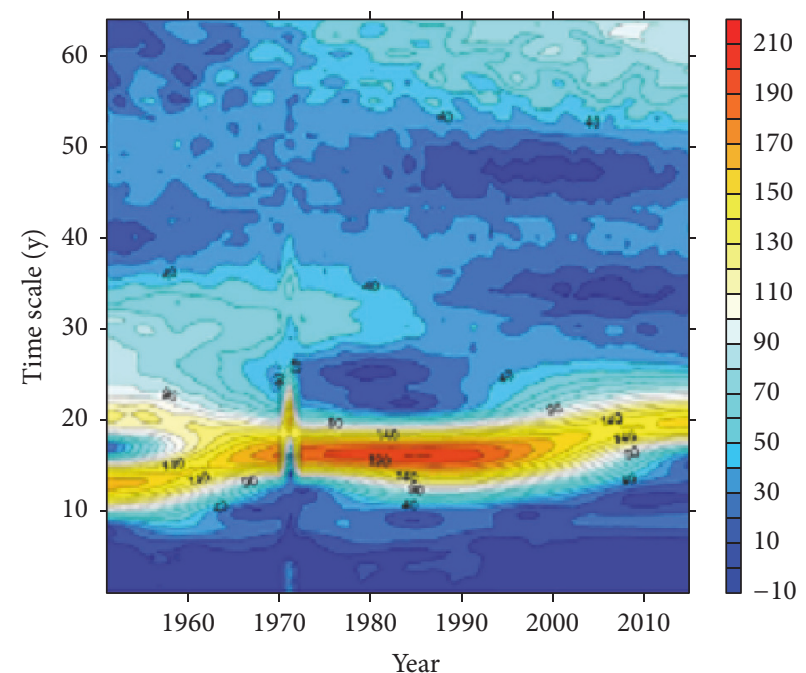

(b)

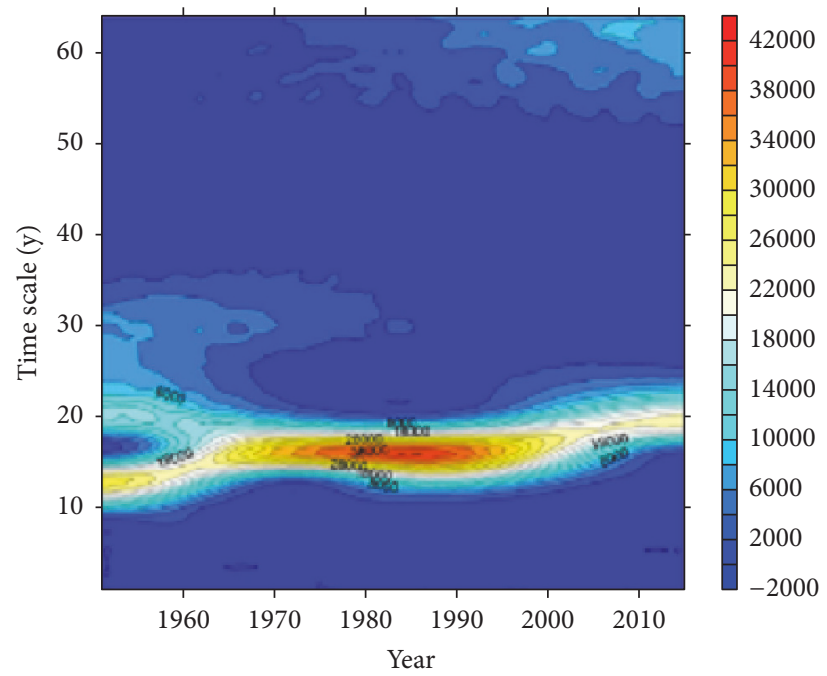

(c)

FIGURE 5: The real part, modulus, and the second modulus power of the wavelet coefficient contour of precipitation: (a) real part wavelet coefficient contour map of sunspot number; (b) modulus of wavelet coefficient contour map of sunspot number; (c) the second modulus power of the wavelet coefficient contour map of sunspot number.

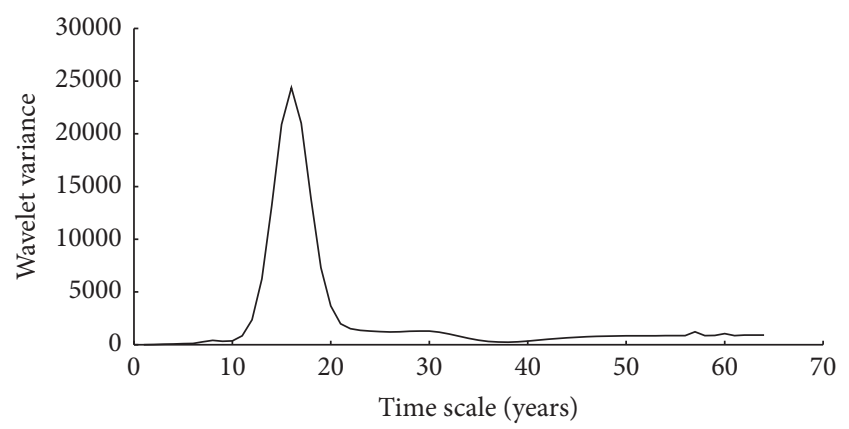

(a)

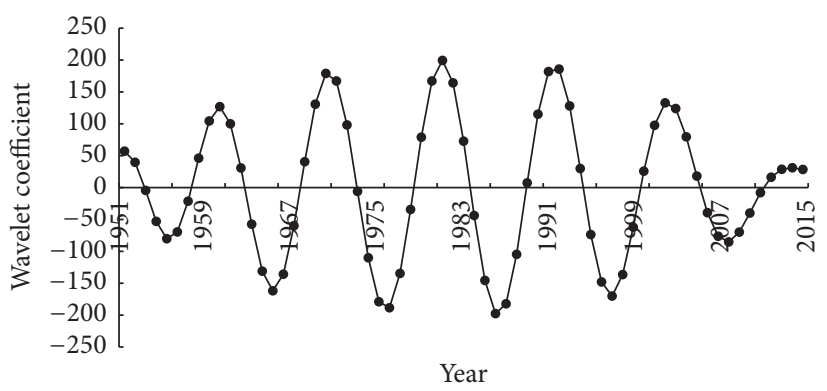

(b)

FIGURE 6: Wavelet variance and real part coefficient changes of sunspot number: (a) wavelet variance of sunspot number; (b) wavelet coefficient changes of sunspot number from 1951 to 2015 on a 16-year scale. 
TABLE 2: El Nino events from 1951 to 2015.

\begin{tabular}{|c|c|c|c|c|}
\hline El Nino events & Starting and ending time & Strength grade & Time span & Occurrence time \\
\hline 1952 & Aug. 1951-Apr. 1952 & Weak & 2 & Summer \\
\hline 1957 & Apr. 1957-Feb. 1958 & Strong & 2 & Spring \\
\hline 1958 & Mar. 1958-Aug. 1958 & Strong & 1 & Spring \\
\hline 1963 & Jul. 1963-Jan. 1964 & Weakest & 2 & Summer \\
\hline 1965 & May 1965-Mar. 1966 & Moderate & 2 & Spring \\
\hline 1968 & Oct. 1968-Mar. 1969 & Moderate & 1 & Autumn \\
\hline 1969 & Apr. 1969-Jan. 1970 & Moderate & 3 & Summer \\
\hline 1972 & Jun. 1972-Mar. 1973 & Strong & 2 & Summer \\
\hline 1976 & Jun. 1976-Nov. 1976 & Weak & 1 & Summer \\
\hline 1977 & Dec. 1976-Mar. 1977 & Weak & 1 & Spring \\
\hline 1982 & Sep. 1982-Nov. 1982 & Strong & 1 & Autumn \\
\hline 1983 & Dec. 1983-Mar. 1983 & Strong & 1 & Autumn \\
\hline 1986 & Oct. 1986-Nov. 1986 & Strong & 1 & Autumn \\
\hline 1987 & Dec. 1987-Mar. 1988 & Strong & 3 & Autumn \\
\hline 1991 & May 1991-Mar. 1992 & Strong & 2 & Spring \\
\hline 1992 & Apr. 1992-Jun. 1992 & Strong & 1 & Spring \\
\hline 1993 & Apr. 1993-Nov. 1993 & Weak & 1 & Spring \\
\hline 1994 & May 1994-Feb. 1995 & Moderate & 2 & Spring \\
\hline 1997 & May 1997-Jul. 1998 & Strongest & 2 & Spring \\
\hline 2002 & May 2002-Mar. 2003 & Moderate & 2 & Spring \\
\hline 2004 & Jul. 2004-Feb. 2005 & Weak & 2 & Summer \\
\hline 2006 & Sep. 2006-Jan. 2007 & Weak & 2 & Autumn \\
\hline 2009 & Jun. 2009-May 2010 & Moderate & 2 & Summer \\
\hline 2012 & Jul. 2012-Nov. 2012 & Weak & 1 & Summer \\
\hline 2015 & May 2015-Dec. 2015 & Strong & 1 & Spring \\
\hline
\end{tabular}

central equatorial Pacific-El Nino, associated with anomalies in equatorial Pacific sea level pressure (SLP) differences, known as the Southern Oscillation $[16,17]$. A large number of recent studies established a correlation between precipitation and El Nino phenomena in the northern hemisphere and northern/northwest China [18-21].

The monthly standardized anomaly of the sea level pressure difference between Tahiti and Darwin, Australia, is defined as the Southern Oscillation Index (SOI), which is a frequently used index of ENSO events [22]. Nino-3.4 is the mean SST in the eastern equatorial Pacific Ocean, which spans $5^{\circ} \mathrm{N} \sim 5^{\circ} \mathrm{S}$ and $170^{\circ} \sim 120^{\circ} \mathrm{W}$. This area best represented the El Nino variability that was used in this study.

As was shown in Table 2, there were 25 El Nino years from 1951 to 2015, among which 10 strong El Nino events occurred. In addition to 1958 and 1983, precipitation significantly declined in strong El Nino years (Figure 7). The other eight strong El Nino events occurred in 1957, 1972, 1982, 1986, $1987,1991,1992$, and 1997, and the corresponding precipitation was in 1957 (397.5 mm), 1972 (310.7 mm), 1982 (460.7 mm), 1986 (446.4 mm), 1987 (489.3 mm), 1991 (453.6 mm), 1992 (460.7 mm), and 1997 (375 mm), respectively. But after dry years, the years following a strong El Nino year showed sharply increased precipitation and an increment of annual precipitation in the Yan'an area. Following the strong El Nino years, the corresponding increments of annual precipitation

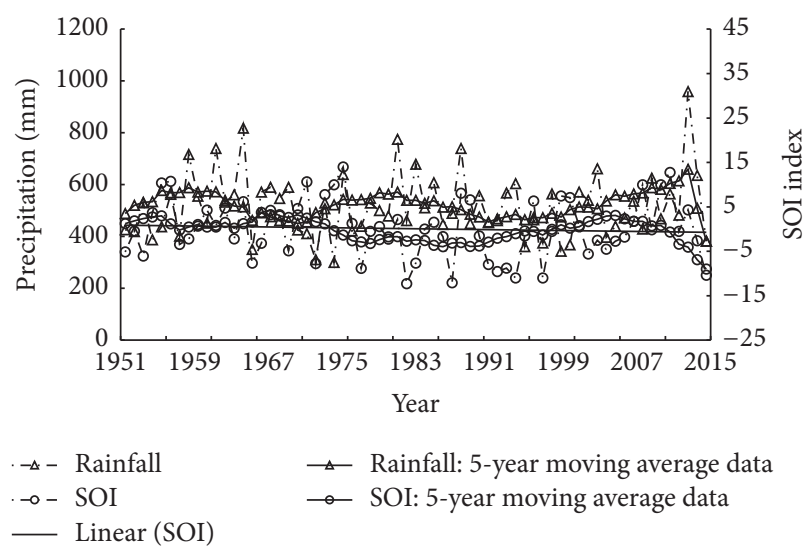

FIGURE 7: Variation in precipitation at Yan'an station and the SOI index from 1951 to 2015. Note. When the SOI was negative, El Nino occurred in the corresponding year.

was in 1958 (317.8 mm), $1973(217.8 \mathrm{~mm}), 1983(217.8 \mathrm{~mm}), 1992$ $(107.1 \mathrm{~mm})$, and $1998(189.3 \mathrm{~mm})$. The increments were all more than $100 \mathrm{~mm}$ and in some years more than $300 \mathrm{~mm}$. In the weak and moderate El Nino years, the precipitation in years following the El Nino year also showed an increasing trend but weaker than the strong El Nino year. Of the strong 
El Nino years, in 1969, precipitation also increased in the same year. Precipitation in 1976 and 1986 showed hysteresis, and precipitation rose in 1978 and 1988. In the consecutive El Nino years 1982 and 1983, the precipitation varied in the second year. Zhu and Li. [23] found that precipitation in northeast China was significantly reduced in the El Nino year but increased sharply in the following year, in agreement with our study. Wu and $\mathrm{Chu}$ [24] indicated that rainstorm days in Beijing increased in the year following El Nino and the next non-El Nino year. Therefore, El Nino had a significant influence on extreme precipitation.

By analyzing the 10-year moving average curves for precipitation and SOI (Figure 7), the negative SOI index was associated with decreasing precipitation and vice versa. As an effective indicator of El Nino, when the SOI was negative, El Nino occurred in the corresponding year. Although precipitation in the year following El Nino increased sharply, the El Nino years constantly suffered from drought. According to the 10-year moving average curves, when El Nino events occurred frequently, the precipitation in the same period showed a general downward trend. From Figure 7, precipitation has been on the rise since 1997. Sayemuzzaman et al. [19] detected decreasing precipitation during February from 2000 to 2009 when the SOI was negative, which is similar to findings in this study and Sayemuzzaman et al. [19].

\section{Conclusions}

This study investigated factors influencing extreme precipitation in typical regions of the Loess Plateau by analyzing daily data from nine weather stations in Yan'an from 1951 to 2015. Wavelet analysis, statistical analysis, and trend detection were applied for periodic analysis and the magnitude of trends.

(1) Based on the time series data (1951-2015), the precipitation at Yan'an station and sunspot number were decomposed using a complex Morlet wavelet. From the analyses of the real part, the modulus, and power of modulus, the precipitation had an obvious periodic variability on the 28-45-year, 51-64-year, and less than 10 -year scales. At every scale, there were different periodical characteristics. Four-year, eight-year, and 41 -year periods were detected within a 64 -year scale from the wavelet variance; the 41-year period was the most obvious. The sunspot number had similar results and showed a 16-year periodic variability. During the period from 1951 to 2015, there were notable correlations between precipitation and sunspot number. The correlation coefficients were 0.784 and 0.893 , respectively. The maximum precipitation occurred mainly at the peak of sunspot number or 2 a near it. Solar activity had significant impacts on precipitation at Yan'an station.

(2) There was also a correlation between precipitation and El Nino phenomena in this study. It was observed that El Nino years often corresponded with droughts. However, extreme precipitation frequently occurred in the year following an El Nino year. By analyzing the 10 -year moving average curves for precipitation and SOI, we found that El Nino events occurred frequently, and generally, the total annual precipitation in the same period showed a downward trend.

The complex Morlet wavelet was used to analyze the wavelet structure of precipitation and the sunspot number. In this research, according to the wavelet coefficient for significant periods, impacts of solar activity on precipitation in typical regions of the Loess Plateau were analyzed, and the important results were obtained. The results presented here are different from those presented previously. At the same time, relationships between precipitation and El Nino were detected, where the latter had important impacts on precipitation. However, the correlation between El Nino and precipitation was lower than between the sunspot and precipitation.

\section{Conflicts of Interest}

The authors declare that they have no conflicts of interest.

\section{Acknowledgments}

This paper was supported by Natural Science Foundation of Shaanxi (2016ZDJC-20), Natural Science Foundation of China (41371276 and 51309194), Knowledge Innovation Project of Institute of Soil and Water Conservation, CAS \& MWR (Soil and Water Conservation Project) (A315021615), and Application of MBER Soil Stabilizer in Road Erosion Prevention of Red Soil Region (K4030217044).

\section{References}

[1] Z.-J. Wang, J.-Y. Jiao, S. Rayburg, Q.-L. Wang, and Y. Su, "Soil erosion resistance of "Grain for Green" vegetation types under extreme rainfall conditions on the Loess Plateau, China," Catena, vol. 141, pp. 109-116, 2016.

[2] P. T. Wu and J. E. Gao, The New Theory of Soil and Water Conservancy in the Loess Plateau, The Yellow River Water Conservancy Press, Zhengzhou, China, 2006.

[3] C. H. Li, Z. F. Yang, G. H. Huang, and Y. P. Li, "Identification of relationship between sunspots and natural runoff in the Yellow River based on discrete wavelet analysis," Expert Systems with Applications, vol. 36, no. 2, pp. 3309-3318, 2009.

[4] P. Gao, X. M. Mu, R. Li, and F. Wang, "Analyses of relationship between Loess Plateau erosion and sunspots based on wavelet transform," Hydrology and Earth System Sciences Discussions, vol. 8, no. 1, pp. 277-303, 2011.

[5] M. A. Al-Tameemi and V. V. Chukin, "Global water cycle and solar activity variations," Journal of Atmospheric and SolarTerrestrial Physics, vol. 142, pp. 55-59, 2016.

[6] S. Yamakawa, M. Inoue, and R. Suppiah, "Relationships between solar activity and variations in SST and atmospheric circulation in the stratosphere and troposphere," Quaternary International, vol. 397, pp. 289-299, 2016.

[7] W. J. R. Alexander, "Linkages between solar activity and climatic responses," Energy and Environment, vol. 16, no. 2, pp. 239-253, 2005.

[8] S. Chaudhuri and J. Pal, "The influence of El Niño on the Indian summer monsoon rainfall anomaly: a diagnostic study of the 
1982/83 and 1997/98 events," Meteorology and Atmospheric Physics, vol. 124, no. 3-4, pp. 183-194, 2014.

[9] E. G. Pavía and A. Badan, "ENSO modulates rainfall in the Mediterranean Californias," Geophysical Research Letters, vol. 25, no. 20, pp. 3855-3858, 1998.

[10] D. B. Percival and A. T. Walden, Wavelet Methods for Time Series Analysis, Cambridge University Press, Cambridge, UK, 2006.

[11] D. Liu, Q. Fu, T. Li, Y. Hu, K. M. Imran, and F. M. Abrar, "Wavelet analysis of the complex precipitation series in the Northern Jiansanjiang administration of the Heilongjiang land reclamation, China," Journal of Water and Climate Change, vol. 7, no. 4, pp. 796-809, 2016.

[12] Y. Wei, J. Jiao, G. Zhao, H. Zhao, Z. He, and X. Mu, "Spatialtemporal variation and periodic change in streamflow and suspended sediment discharge along the mainstream of the Yellow River during 1950-2013," Catena, vol. 140, pp. 105-115, 2016.

[13] C. H. Li and Z. F. Yang, "Relationship between sun activities and natural runoff Yellow river basin based on morlet wavelet," Journal of Water Resources \& Water Engineering, vol. 15, no. 3, pp. 1-4, 2004.

[14] X. N. Zhang, X. M. Shi, and S. Y. Yang, "Relationship between number of sunspots and rainfall in Xi'an in summer and autumn," Arid Zone Research, vol. 30, no. 3, pp. 485-490, 2013.

[15] A. Prestes, N. R. Rigozo, E. Echer, and L. E. A. Vieira, "Spectral analysis of sunspot number and geomagnetic indices (1868-2001)," Journal of Atmospheric and Solar-Terrestrial Physics, vol. 68, no. 2, pp. 182-190, 2006.

[16] E. M. Rasmusson and T. H. Carpenter, "Variations in tropical sea surface temperature and surface wind fields associated with the Southern Oscillation/El Niño," Monthly Weather Review, vol. 110, no. 5, pp. 354-384, 1982.

[17] K. E. Trenberth and T. J. Hoar, "El Niño and climate change," Geophysical Research Letters, vol. 24, no. 23, pp. 3057-3060, 1997.

[18] J. W. Hurrell, "Decadal trends in the North Atlantic Oscillation: regional temperatures and precipitation," Oceanographic Literature Review, vol. 2, no. 43, p. 116, 1996.

[19] M. Sayemuzzaman, M. K. Jha, A. Mekonnen, and K. A. Schimmel, "Subseasonal climate variability for North Carolina, United States," Atmospheric Research, vol. 145-146, pp. 69-79, 2014.

[20] Y. Yuan, H. Yang, and C. Y. Li, "Study of El Nino events of different types and their potential impact on the followingsummer precipitation in China," Acta Meteorolotica Sinica, vol. 70, no. 3, pp. 467-478, 2012.

[21] P. F. Zhang and J. B. Zhao, "The influence of El Nino/La Nina events on climate of Shanxi Province," Journal of Arid Land Resources and Environment, vol. 26, no. 2, pp. 74-78, 2012.

[22] W. Y. Chen, "Assessment of Southern Oscillation sea-level pressure indices," Monthly Weather Review, vol. 110, no. 7, pp. 800-807, 1982.

[23] B. Y. Zhu and D. H. Li, "The relationship between the El Nino events and the drought or excessive rain of northwest China during 1845 to 1988," Scientia Atmospherica Sinica, vol. 16, no. 2, pp. 185-192, 1992.

[24] Z. H. Wu and S. L. Chu, "Synoptical analysis of the torrential rain over the southern Haihe River-basin during August 1996," Acta Meteorolotica Sinica, vol. 24, no. 5, pp. 14-18, 1998. 

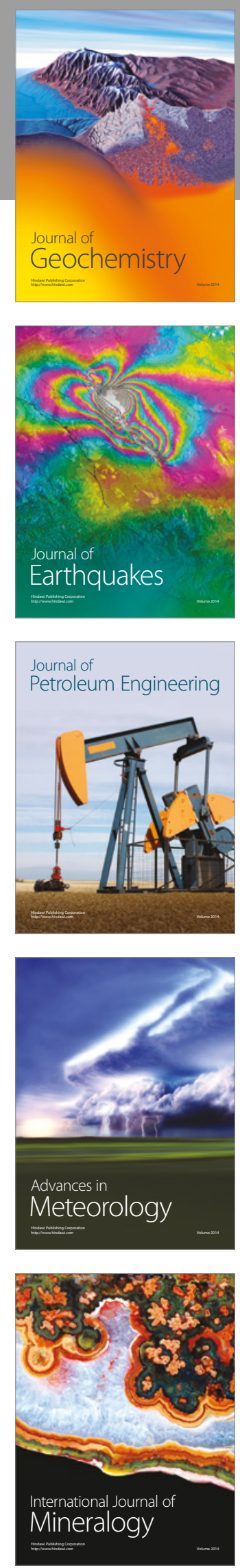
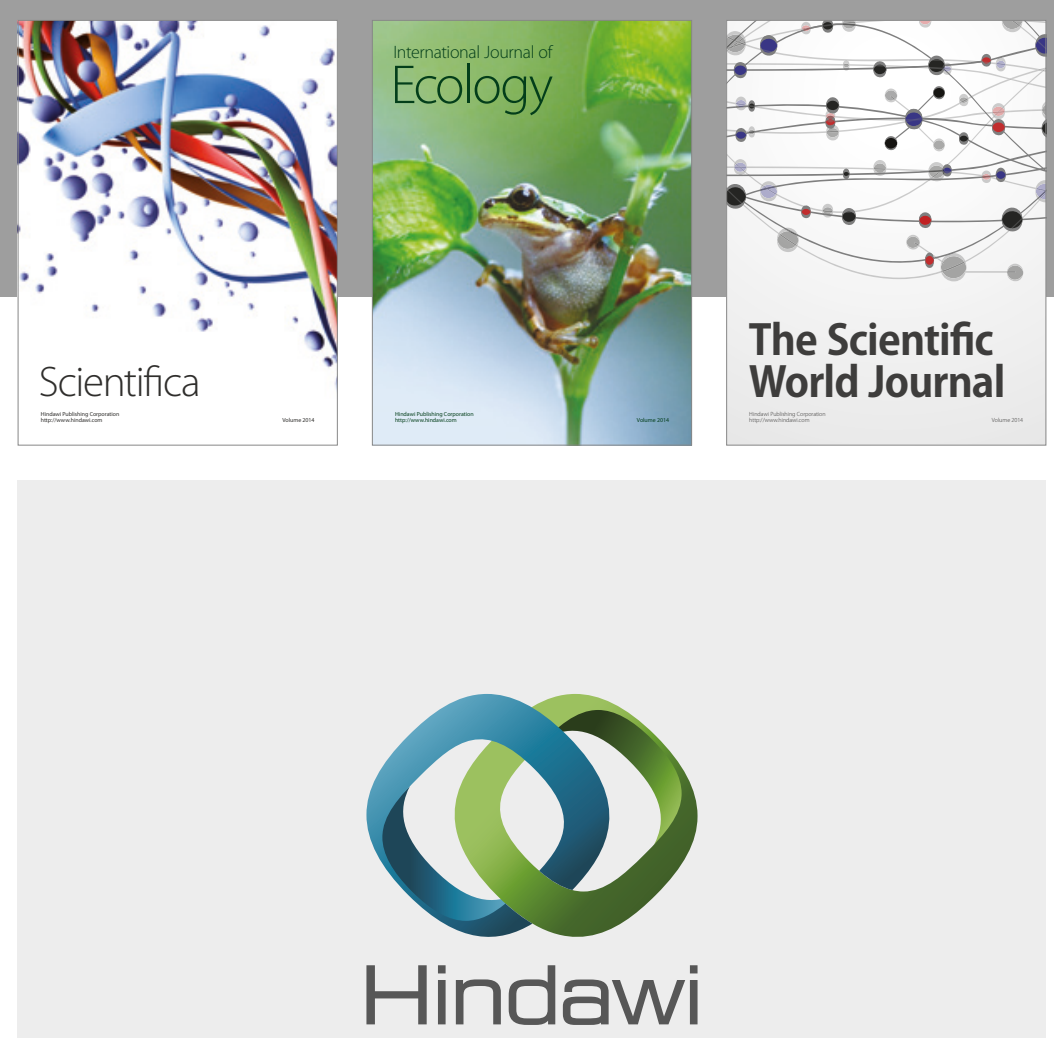

Submit your manuscripts at

https://www.hindawi.com
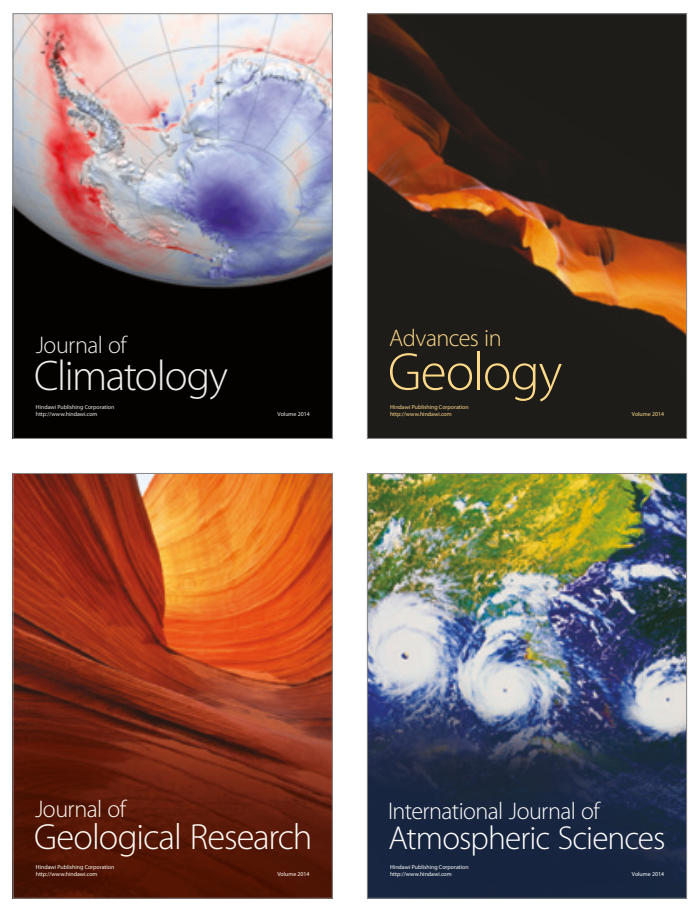

The Scientific

World Journal
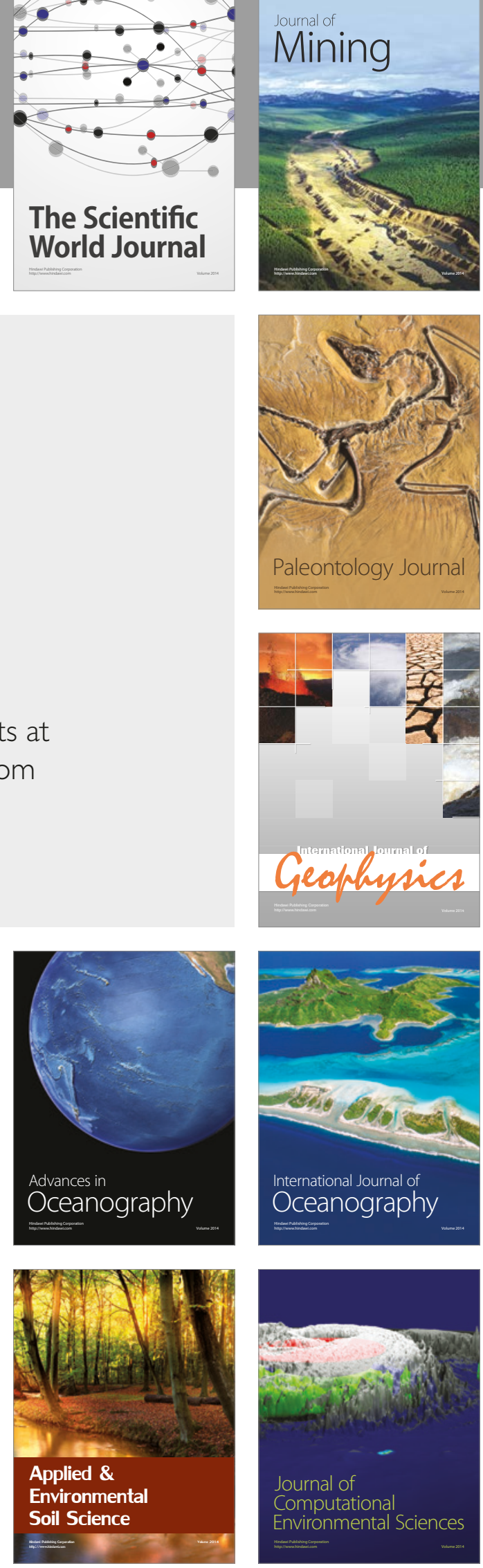